\title{
Audit in general practice by a receptionist: a feasibility study
}

\author{
Ben Essex, Jo Bate
}

\begin{abstract}
Objective-To examine whether audit can be done cost effectively by a practice's receptionist.

Design - The practice set goals for various aspects of care, and forms were devised for the receptionist to collect, analyse, and present data to assess whether these goals had been achieved in the
\end{abstract} previous year.

Setting-Six doctor practice in south London looking after 11500 patients.

Main outcome measures-Ability of receptionist to present data showing the level of attainment of the practice's goals; time spent on audit by receptionist each week.

Results - The practice set goals for immunisation; follow up of patients with abnormal cervical smears; frequency of recording of blood pressure and smoking habit; screening of patients over 75; care of diabetic patients and patients with serious mental illness; antenatal care; variations in workload; and availability of appointments. The receptionist was able to audit all these tasks in four hours a week; this increased her job satisfaction and extended her skills. A small amount of regular supervision was necessary-roughly 30 minutes a week in the first year of the study and $\mathbf{3 0}$ minutes a fortnight in the second-to ensure accuracy and deal with any difficulties that arose.

Conclusion-The method developed enabled a receptionist to audit aspects of the practice cost effectively. There is great scope for enlarging the conventional role of the receptionist.

\section{Introduction}

Audit is now an integral part of good medical practice, and its basic principles have been clearly defined. ${ }^{1-3}$ Recent debate has focused on what to audit and what to measure. ${ }^{+6}$ There is growing recognition of the need to delegate the collection of data to practice staff whenever possible, ${ }^{7}$ but there has been little discussion about the feasibility of this or the conditions under which it can safely be done. Over the past two years we have conducted a research project to design and evaluate the feasibility and cost effectiveness of an audit system that can be used by a practice's receptionist devoting just a few hours to it each week.

Sydenham Green Health Centre, London SE26 4TG Ben Essex, FRCGP, general practitioner

Jo Bate, BED, practice receptionist

Correspondence to: $\mathrm{Dr}$ Essex.

BM7 1991;302:573-6

\section{Methods}

The study was undertaken in a practice comprising six doctors looking after 11500 patients. For the past six years the practice has employed a health visitor to screen patients over 75 . Although cervical smears were taken by all the partners, one doctor was responsible for the overall coordination of this service. The responsibility for care of diabetic patients and patients with severe mental illness (schizophrenia and other psychoses) was shared. Disease registers were kept for these conditions. Antenatal care was the specific
Practice's goals for tasks being audited

Immunisation $\quad 90 \%$ Coverage of children under 5

Abnormal results of Follow up of all patients with cervical smear tests severe abnormalities and follow up of $90 \%$ of those with mild or moderate abnormalities to ensure appropriate managemen

Hypertension and $80 \%$ Of patients aged $40-65$ to smoking have had their blood pressure and smoking habit recorded within past three years

Diabetic follow up All diabetic patients under care of general practitioner to have had complete annual review with data on complications recorded

Serious mental $\quad 75 \%$ Of patients with illness schizophrenia and other psychotic illnesses on disease register to have been reviewed within past six months to assess current mental state, treatment needs, and compliance

Screening elderly $\quad 80 \%$ Of patients aged over 75 to people have been screened by health visitor once within past five years

Availability of Wait for non-urgent

appointments appointments to be less than 36 hours for $90 \%$ of surgeries

interest of three doctors. For the past six years the practice has undertaken opportunistic screening of all patients aged over 40 for hypertension and to review their smoking habit. When this study was done the practice was not computerised. The receptionist chosen to participate in the study was paid for an extra four hours' work devoted to audit each week.

A system was devised whereby the receptionist could audit immunisation; action taken in response to reports of abnormalities in cervical smears; the frequency with which blood pressure and smoking habit were recorded; screening for problems in elderly people; care of diabetic patients and patients with serious mental illness; antenatal care; variations in workload; and the availability of appointments. The practice had clearly defined goals for these tasks (box). The audit was to see whether these goals were achieved. Only after measurable goals have been identified can the most relevant observations needed to audit their attainment be selected. Thus for each goal the most relevant observations for the receptionist to record were decided by all concerned in the practice.

Once the goals had been identified and the observations selected the next step was to design forms for collecting data that were easy for the receptionist to use. This was done in collaboration with a consultant statistician, who also advised on all aspects of sampling, collecting data, analysis, and presentation. Two sorts 


\begin{tabular}{|c|c|c|c|c|c|c|c|c|c|c|c|c|}
\hline \multirow[b]{2}{*}{ Name } & \multirow{2}{*}{$\begin{array}{l}\text { Date of } \\
\text { delivery }\end{array}$} & \multicolumn{3}{|c|}{ Deliveries } & \multicolumn{2}{|c|}{ Booked } & \multicolumn{2}{|c|}{ Delivered } & \multirow[t]{2}{*}{ Booking risk } & \multirow[t]{2}{*}{ New risk factors } & \multicolumn{2}{|c|}{ Outcome } \\
\hline & & Normal & $\begin{array}{l}\text { Caesarean } \\
\text { section }\end{array}$ & Other & Home & Hospital & Home & Hospital & & & Baby & Mother \\
\hline & & & & & & & & & & & & \\
\hline & & & & & & & & & & & & \\
\hline & & & & & & & & & & & & \\
\hline & & & & & & & & & & & & \\
\hline
\end{tabular}

Diabetes

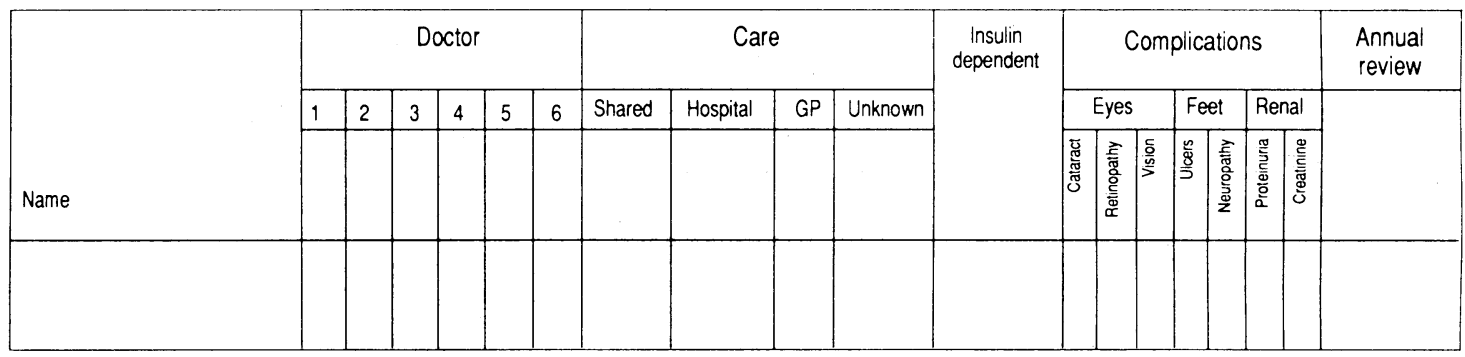

Care of elderly people

\begin{tabular}{|c|c|c|c|c|c|c|c|c|c|c|c|c|c|c|c|c|c|c|c|}
\hline & & 1 & 2 & 3 & 4 & 5 & 6 & 7 & 8 & 9 & 10 & 11 & 12 & .13 & 14 & 15 & 16 & 17 & 18 \\
\hline Name & Problem & & & & & & & & & & & & & & & & & & \\
\hline Date of birth & Referral & & & & & & & & & & & & & & & & & & \\
\hline Screened on & Services & & & & & & & & & & & & & & & & & & \\
\hline
\end{tabular}

FIG 1-Data collection forms for audits of antenatal care, care of patients with diabetes, and screening of elderly people

\begin{tabular}{|c|c|c|c|}
\hline \multicolumn{4}{|c|}{ 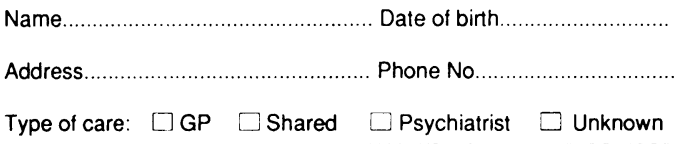 } \\
\hline Management & Yes & No & Unknown \\
\hline Current treatment - needs drugs & $\square$ & $\square$ & $\square$ \\
\hline - takes drugs & $\square$ & $\square$ & $\square$ \\
\hline Admission in past year & $\square$ & $\square$ & $\square$ \\
\hline Follow up - seen in past 6 months by GP & $\square$ & $\square$ & $\square$ \\
\hline $\begin{array}{l}\text { If yes, was mental state } \\
\text { recorded? }\end{array}$ & $\square$ & $\square$ & $\square$ \\
\hline $\begin{array}{l}\text { - seen in past } 6 \text { months by } \\
\text { psychiatrist or community } \\
\text { psychiatric nurse }\end{array}$ & $\square$ & $\square$ & $\square$ \\
\hline $\begin{array}{l}\text { If taking lithium, blood test done in } \\
\text { past } 12 \text { months? }\end{array}$ & $\square$ & $\square$ & $\square$ \\
\hline $\begin{array}{l}\text { Problem now inactive - that is, mental } \\
\text { state continuously normal for } 12 \text { months }\end{array}$ & $\square$ & $\square$ & $\square$ \\
\hline
\end{tabular}

FIG 2-Data collection form for audit of care of patients with mental illness

of form were developed for each audit: one for collecting the initial data (figs 1 and 2) and one for analysing and presenting them. When many observations had to be recorded they were coded to simplify the collection of data. This was done for antenatal risk factors and for problems, referrals, and services relating to screening elderly people (figs 3 and 4).

Data on immunisation came from the practice's agesex register, the district health authority's computer printout, and the patients' records. For the audits of care of diabetic and mentally ill patients the patients were identified from the disease registers. The patients' records were the source of most of the data. Reports of cervical smear tests were filed in the records, but patients with abnormal smears also had a card in a box file, which provided details of the abnormality and follow up.

In the first year the receptionist determined how many of the data were accessible. We met regularly to identify difficulties at an early stage. When no information was available in the records the receptionist asked the relevant doctor, health visitor, or nurse. As a result of this pilot study some of the forms were redesigned. The receptionist kept a record of how long each audit took; the feasibility of.doing these audits in four hours a week could then be assessed. In the second year the audits were repeated, using the redesigned data collection forms. The methods had been refined, and as a result the audit was done efficiently and required much less supervision.

\section{Results}

Immunisation-Children born between 1 April 1988 and 31 March 1989 would have been expected to have completed their immunisations by June 1990. It was easy to identify this cohort from the practice's age-sex register. Discrepancies between data on the register and on the printout from the district health authority's computer were identified. Both were then amended by the receptionist. Information from the data collection forms was then transferred to simple tables, which provided information about the place of immunisation. The receptionist identified children who had not been vaccinated or in whom immunisations were incomplete. She identified seven outcomes: recalled once but did not attend; recalled twice but did not attend; refusal recorded; visited by health visitor; records indicated that mother had been reminded; no action taken; family moved. This audit was straightforward and showed that $86 \%$ of children in this cohort had completed their vaccinations.

Abnormal cervical smears-The receptionist identi- 
fied the 465 patients who had had abnormalities in cervical smears taken during 1985-9. These were divided into three groups: inflammatory smear, mild or moderate dyskaryosis, and severe dyskaryosis. Patients in each group were further classified according to eight outcomes: rescreened within three, six, 12, or 15 or more months; referred for colposcopy; on a waiting list for colposcopy; colposcopy done or not; hysterectomy done; recalled but did not attend; not recalled; unknown. These data were presented in the form of a simple table.

Patients with diabetes - The data collection form for care of diabetic patients worked well and needed only minor revision. The receptionist used the disease register to identify the 136 diabetic patients, and their records were then reviewed. She provided the practice with a breakdown of type of care-that is, general practitioner only, hospital only, shared, or unknown. For diabetic patients cared for entirely by their general practitioner data on complications were readily

\begin{tabular}{|l|l|}
\hline Risk factors at booking & Risk factors during pregnancy \\
Social & 33 Gestational diabetes \\
1 Single parent & 34 Pregnancy induced \\
2 Smokes $>10$ cigarettes / day & hypertension \\
3 Alcohol / drug problem & 35 Antepartum haemorrhage \\
4 Age $>35$ & 36 Mental illness \\
5 Age $<18$ & 37 Twins \\
6 Other & 38 Breech presentation \\
& 39 Polyhydramnios \\
Medical & 40 Rhesus antibodies \\
7 Hypertension & 41 Small for dates \\
8 Diabetes & 42 Other \\
9 Heart disease & \\
10 Renal disease & \\
11 Haemoglobinopathy & \\
12 Serious mental illness & \\
now or in past & \\
13 Genetic disorder or previous & Outcomes \\
congenital abnormality & Baby \\
14 Carrier of hepatitis B virus & 43 Live, normal weight \\
15 Hiv risk & 44 Miscarriage \\
16 History of deep vein thrombosis & 45 Intrauterine death \\
or embolus & 46 Stillbirth \\
17 Genital herpes & 47 Perinatal death \\
18 Risk of osteomalacia & 48 Low birth weight (<2500 g) \\
19 Other & 49 High birth weight ( $>4500 \mathrm{~g})$ \\
Obstetric & 50 Breast fed \\
\hline Past history of: & 51 Bottle fed \\
20 Rhesus antibodies & 52 Other \\
21 Caesarean section & \\
22 Pregnancy induced hypertension & Mother \\
23 Low birth weight $<2500 \mathrm{~g})$ & 53 No problems \\
24 High birth weight $(>4500 \mathrm{~g}$ ) & 54 Postpartum haemorrhage \\
25 Stillbirth & 55 Retained placenta \\
26 Perinatal death & 56 Infection and readmission \\
27 Antepartum haemorrhage & 57 Third degree tear \\
$28>5$ Pregnancies & 58 Depression within 6 weeks \\
29 Weight < $45 \mathrm{~kg}$ & of childbirth \\
30 Weight $>85 \mathrm{~kg}$ & 59 Housing problems \\
31 Height $<152 \mathrm{~cm}$ & 60 Sexual difficulties \\
32 Other & 61 Other \\
\hline
\end{tabular}

FIG 3-Codes for audit of antenatal care

\begin{tabular}{|lll|}
\hline & Referrals & Services \\
Problems & 1 Occupational therapist & 1 Meals on wheels \\
1 Lives alone & 2 District nurse & 2 Home help \\
2 Housing & Social workers: & 3 Voluntary services \\
3 Financial & 3 For deaf & 4 Age Concern \\
4 Dementia & 4 For blind & 5 Social services \\
5 Depression & 5 Generic & 6 Day centre \\
6 Visual & Chiropody: & 7 Lunch club \\
7 Deafness & 6 Domiciliary & 8 Housing \\
8 Mobility & 7 Clinic & 9 Respite care \\
9 Bladder & 8 Psychogeriatric team & 10 Red Cross \\
10 Dental & 9 General practitioner & 11 Holidays \\
11 Chiropody & 10 Community physiotherapist & 12 Bereavement counselling \\
12 Heating & 11 Dentist & 13 Environmental health \\
13 Cooking, cleaning & 12 Religious leader & 14 Transport \\
14 Dressing, bathing & 13 Ophthalmologist & 15 Aids including wheelchair \\
15 Other & or optician & 16 Benefits, claims \\
& 14 Audiology & 17 Repeat prescriptions and \\
& 15 Other & number of items \\
& & 18 Carers group \\
& & 19 Other \\
& &
\end{tabular}

FIG 4-Codes for audit of screening of elderly people obtained. For patients under hospital care, however, an annual report was not always sent. Hospital letters often failed to record complications. In such cases the receptionist sent a proforma letter to the diabetic department asking for an updated report. Patients under the care of their general practitioner who had not had an annual review were brought to the doctor's attention.

Screening of elderly people - The data collection form for elderly people was completed by the health visitor when each patient was screened. It provided all the relevant information about problems identified and referrals and services organised as a result of screening during the year. It was then easy for the receptionist to collate this information and calculate rates from the health visitor's data based on the total number of patients over 75 .

Hypertension and smoking - To audit the recording of blood pressure and smoking habit the receptionist took a random one in four sample of 50 men and 50 women in each five year age group from 40 to 65 . This gave confidence limits of $10 \%$. The notes were examined to find out whether the blood pressure had been checked within the previous three years and smoking behaviour had been recorded. These data were tabulated by five year age group and sex. They were easy to analyse and were plotted to show trends.

Mental illness - The audit of mental illness had to be done jointly by the receptionist and the doctor most concerned in long term care. The disease register was used to identify 70 patients with schizophrenia or other forms of psychotic illness. Information about the type of care, current mental state, need for drugs, compliance, and hospital follow up was not always available. In such cases the doctor was asked for further details. After analysis of all available data and discussion with the relevant doctors treatment needs and current mental state were unknown for 22 of the patients on the register. This information enabled follow up to be organised.

Workload-Data on workload were collected weekly to identify the variations in consultations (routine and emergencies) and home visits during the year. Information was available, on a daily basis, whenever the wait for non-urgent appointments exceeded 36 hours. This provided an audit of the accessibility of appointments throughout the year. The results were presented in graph format.

\section{Discussion}

Audit helps to answer basic questions about what is done and what the outcomes are. It also facilitates comparisons with what was done previously. This shows whether change has occurred in the right direction-whether it has "closed the loop." We found that once goals had been identified by the practice well designed data collection forms enabled the receptionist to undertake audits to show whether the practice had achieved those goals. By plotting the data comparisons could then be made with performance in the previous year.

In the first year we needed a fixed appointment for 30 minutes every week to review the methods of collecting data, deal with any problems or difficulties that arose, and revise the data collection forms when necessary. During the second year we had a fixed appointment every two weeks, which lasted on average 30 minutes.

Information needed for the audit was initially kept in many different places, and finding it was often time consuming. The data collection forms provided a centralised source of information. Doctors in the antenatal clinics and the health visitor screening elderly people started to use the forms as they provided a rapid method of recording information daily. This 
greatly simplified the receptionist's task of collating the data. When the practice is fully computerised the audits-particularly of the management of patients with abnormal cervical smears - will be quicker to do. Information technology is expensive, and how it is to be financed is not clear. ${ }^{10}$ When done by doctors audit is expensive. The receptionist found it quite feasible to do the audits described here in four hours a week as part of her general duties. The cost at $£ 5.20$ an hour came to $£ 960$ a year. This was for a practice of six doctors. After deduction of reimbursements and tax it came to $£ 30$ per doctor per year. This is a cost effective way of doing such audits. Moreover, whether the doctors would have been prepared to devote the 200 hours a year that seemed necessary for this activity is doubtful. The receptionist found the work interesting. It gave her new skills and greater insight into the practice's activities.

This method of collecting data provided the practice with vital information about the attainment of goals related to a wide range of services. There is now great scope for enlarging the conventional role of the receptionist. We designed our forms for collecting and presenting data to meet our practice's goals; other practices will have different goals, but our forms can be readily adapted to meet the needs of other practices.
We are preparing a manual that describes this work in more detail and may help to train receptionists who are interested in acquiring skills in audit.

We thank South East Thames Regional Health Authority for the grant for this research; Professor Michael Healy for expert advice; the partners in the practice, Drs $\mathrm{S}$ Ebrahim, $\mathrm{H}$ Graver, A Platman, J Sikorski, and S Thomas, and Mrs Jen Cruse for their participation; and Dr Rodney Turner and Mrs Lesley Elliott of the Primary Care Development Fund for their support.

1 Shaw CD, Costain DW. Guidelines for medical audit: seven principles. $B M f$ 1989;299:498-9.

2 Donabedian A. Evaluating the quality of medical care. Millbank Memoria Fund Quarterly 1966;44 (suppl):166-206.

3 World Health Organisation. The principles of quality assurance. Copenhagen WHO European Office, 1990. (EURO reports and studies 94 .)

4 Pendleton D, Scholfield T, Marinker M, eds. In pursuit of quality. London: fournal of the Royal College of General Practitioners, 1986.

5 Buckley G. Quality assessment or quality control. $\mathcal{I} R$ Coll Gen Pract 1989;39:309-12.

6 Marinker M, ed. Medical audit and general practice. London: BM7, 1990.

7 Difford F. Defining essential data for audit in general practice. $B M \gamma$ 1990;300:92-4.

8 Whalen $\mathrm{M}$, ed. The practice receptionist's programme. Oxford: Radcliffe Medical, 1989.

9 Smith T. Medical audit. BMF 1990;300:65

10 Bosanquet N. Quality of care in general practice: lessons from the past. J R Coll Gen Pract 1989;39:88-9.

(Accepted 6 February 1991)

\section{MIRROR OF MEDICINE}

In $1911 \mathrm{H}$ (ugo) Massac Buist began his long association with the Fournal as its motoring correspondent. Buist was then only 33 , but he already had achieved much as a motoring, boating, and aviation pioneer. In 1904 he made the world's first motor mountaineering tour; in the following year he established, with Charles Rolls, the London-Monte Carlo record. He then took part in the first cross Channel motor boat trial before taking up ballooning and flying. He wrote "thousands" of articles for many journals on aviation, motoring, and manufacturing problems

Buist was a prolific contributor to the $B M \mathcal{H}$. His first articles dealt with the 10th "International Motor Carriage Show," which was promoted by the Society of Motor Manufacturers and Traders at Olympia in 1911. The main object, indeed, Buist's main object over the many years that he wrote for the fournal, was to provide authoritative advice to doctors considering buying a car. In 1912 Buist covered not only the motor exhibition but also the "cycle car" and motor cycle show at Kensington "for the medical man of slender means." From 1914 he began to write on more general motoring questions, hitherto largely the preserve of the Fournal's correspondence columns. Thus, in the first half of the year he contributed pieces on fuel for medical men's motor cars, some phases of the light car problem, the multiplication of accessories, lessons of the light car trials, and lessons of the tourist trophy race. By this time Buist was providing virtually all of the fournal's motoring "copy."

The outbreak of war did not restrict his contributions, for not only did he continue to produce his usual column, he also started a series on motor ambulances and wrote on such questions as the requisitioning of motors and the fuel problem. In the second half of 1914 Buist published 10 articles, running to some 23000 words. The contraction in British production of non-military vehicles and the impossibility of obtaining imported models during the war led to a dramatic shrinkage of the "motor cars for medical men" series from early 1915, though Buist still wrote on military ambulances and discussed the implications of fuel shortages, lighting regulations, and the problem of obtaining spare parts.

After the war Buist reported on the Paris and Olympia motor shows. He found that, while quality was higher than in 1914, the price of cars had outstripped the average increase in medical incomes. Nevertheless, he was able to list a range of cars priced between $£ 195$ and $£ 800$ which might attract medical visitors to Olympia. Buist's articles of ten stressed the overseas competition faced by British manufacturers such as Rover, Wolsley, Morris, and Standard, and made a point that was to be made time and again by the domestic industry over the decades, "that we are sending money overseas for a number of commodities which we could produce at home. If we do not order from home sources tens of thousands of skilled workers fail to secure work and, therefore, go on the dole; hence there is a double bill to pay, one direct and the other indirect." As early as 1919 Buist was speculating on the circumstances that might lead to Japanese domination of the world motor industry.

From Mirror of Medicine: A History of the BMF by $\mathrm{P} W \mathrm{~J}$ Bartrip. Published jointly by the $B M \mathcal{F}$ and Oxford University Press; BMA members' price UK $£ 29$, overseas $£ 33$, including postage. Obtainable from the Publishing Manager, $B M \mathcal{F}, \mathrm{PO}$ Box 295, London WC1H 9TE. Non-members UK $£ 35$. Obtainable from OUP Distribution Services, Saxon Way West, Corby, Northamptonshire NN18 9ES. 